\title{
Effects of ginger along with exercise training on serum levels of ALT and AST liver enzymes and malondialdehyde and the activity of liver tissue superoxide dismutase in male Wistar rats
}

\author{
Aghaali Ghasemnian $^{1^{*}}{ }^{(\mathbb{D}}$ Zeinab Iddehloei $^{\circledR}$, Ahmad Rahmani $^{3^{(\mathbb{D}}}$, Mozhgan Usefpour $^{\mathbf{D}^{(\mathbb{D}}}$ \\ ${ }^{1}$ Associate Professor, Department of Sports Sciences, Faculty of Humanities, University of Zanjan, Zanjan, Iran. \\ ${ }^{2}$ Master Student in Exercise Physiology, Zanjan University, Zanjan, Iran. \\ ${ }^{3}$ Assistant Professor, Department of Sports Sciences, Faculty of Humanities, University of Zanjan, Zanjan, Iran. \\ ${ }^{4} \mathrm{MSc}$ student of Sports Physiology, Zanjan University, Zanjan, Iran.
}

*Corresponding Author: Aghaali Ghasemnian, Department of Sports Sciences, Faculty of Humanities, University of Zanjan, Zanjan, Iran.Tel/Fax: 02433054185, Email: ghasemnian@znu.ac.ir

\begin{abstract}
Background and aims: The purpose of this study was to examine the effect of 2 months of endurance training (ET) along with ginger consumption on the serum levels of liver enzymes (ALT and AST), enzymatic activity of superoxide dismutase, and malondialdehyde (MDA) in liver tissue in male Wistar rats.

Material and Methods: 40 adult male Wistar rats were randomly divided into 5 groups according to the weight as follows: control ( $n=8)$, sham $(n=8)$, ET $(n=8)$, ginger $(n=8)$, and ET + ginger $(n=8)$. The training protocol was an ET program on a treadmill for two months $(5$ days a week). Besides standard water and food, in groups using the supplement, $100 \mathrm{mg}$ of ginger solution per $\mathrm{kg}$ body weight of the rats was injected three days a week. Then, 48 hours after the last training session and after 8 hours of fasting, blood and tissue samples were collected over night and the serum levels of liver enzymes (ALT and AST), MDA level of the liver tissue, and activity of the liver superoxide dismutase (SOD) were measured. One-way ANOVA and Tukey post-hoc test were used for data analysis.

Results: The results showed that after 8 weeks, the activity of liver SOD in ET group $(131.7 \pm 18.6, P=0.001)$ and ET + Ginger group $(130.2 \pm 31.3, P=0.001)$ significantly increased in comparison with the control group (83.8 \pm 14.9$)$. Moreover, liver MDA levels in the ET group $(0.38 \pm 0.08, P=0.008)$ and $\mathrm{ET}+$ Ginger group $(0.37 \pm 0.09, P=0.013)$ significantly increased in comparison with the control group (0.25.0 \pm 03$)$. However, 8 weeks of ET coupled with ginger consumption had no effects on the serum levels of AST and ALT $(P>0.05)$. Furthermore, ginger had no effect on MDA level and enzymatic activity of SOD $(P>0.05)$.

Conclusion: This study does not support the protective effects of ginger on the reduction of liver enzymes levels and improvement of the antioxidant status.

Keywords: Endurance exercises, Ginger, Liver enzymes, MDA, Superoxide dismutase
\end{abstract}

Received: 29 July 2019, Accepted: 26 October 2019, ePublished: 29 April 2020

\section{Introduction}

Doing intense physical activity increases the production of reactive oxygen species and leads to oxidative damage (1). The most destructive effect of free radicals has been reported on the cell membrane and membrane of the intracellular organelles, such as mitochondrial membranes. Damage to the phospholipid membrane of the cell ends in peroxidation of the membrane lipid, bringing about the development of some diseases by the production of lipid peroxidation products such as malondialdehyde (MDA) and creatine kinase (2). Among the antioxidant enzymes, superoxide dismutase (SOD) is the first protective enzyme against oxidative stress and by deletion of a large percentage of free radicals produced in the body (3), it decreases the damage of oxidative stress (4). Nonetheless, it has been reported that prolonged and severe exercises are accompanied by oxidative stress, lipid peroxidation, and inadequate antioxidant defense system (5). The liver is one of the tissues exposed to damage from oxidative stress. It has a vital role in maintaining the homeostasis of the body during rest and physical activity. Moreover, the activity of the cells of this tissue while exercising include increasing the conversion of glucogenic amino acids to citric acid cyclones or intermediates, increasing glycogen content to maintain blood glucose and increased fatty acid decomposition to acetyl acetate and ketone to translate

(C) 2020 The Author(s); Published by Shahrekord University of Medical Sciences. This is an open-access article distributed under the terms of the Creative Commons Attribution License (http://creativecommons.org/licenses/by/4.0), which permits unrestricted use, distribution, and reproduction in any medium, provided the original work is properly cited. 
into environmental tissues and meet energy requirements (6). The activity of the liver during exercise, oxygen consumption and production of free radicals in the liver tissue increase more than 2 to 3 times the normal state (6). This leads to reduced levels of antioxidants enzymes, nonenzymatic antioxidants, and oxidative stress in the tissue and damage to lipids, proteins, and cellular DNA and impaired liver function (7). The most sensitive and profitable diagnostic enzymes of the liver are aminotransferases including aspartate aminotransferase (AST) and alanine aminotransferase (ALT) (8). Generally, certain amounts of these enzymes are produced by liver cells, yet after liver damage, the liver cells increase the secretion of the enzymes and their plasma levels, whose increased level is a sign of liver damage (8). The incidence of oxidative stress in the body has other negative effects, such as accelerating aging, the emergence of some neurodegenerative diseases, muscular and lymphoid trauma, tissue inflammation, muscle fatigue, early restlessness, impaired and decreased immune function, and muscle oxidation (9). However, antioxidant supplements may be useful in preventing these disorders by reducing the production of active oxygen species, blocking lipid peroxidation, and boosting the antioxidant defense system (10). However, several studies have reported lack of effects of synthetic antioxidants (11). Hence, the attitude of athletes to use antioxidants of natural origin as well as the effective performance of synthetic antioxidants in reducing the levels of active oxygen species (12), ease of access, lack of side effects and reasonable prices have always been discussed and studied by researchers over the last few decades as alternatives to synthetic drugs. Among these plants are ginger with antioxidant, anti-inflammatory, analgesic (13), immune regulatory, anti-apoptotic, and antinausea effects (14-16). Considering the importance of liver tissue (17), the relationship between active oxygen species and the production of antioxidants, along with widespread interest in replacing natural supplements, especially the physical activity and exercise, there is very little information about the effect of ginger and endurance training (ET) on liver health. The present study is an attempt to examine the effect of ginger extract supplementation and ET on liver and lipid peroxidation, hepatic SOD in liver tissues, and liver enzymes in male Wistar rats.

\section{Methods and Materials \\ Animals}

In this experimental study, 40 male Wistar male rats aged 8 weeks (adult) were purchased from Pasteur Institute (Iran) and transferred to the Applied Sports Physiology Laboratory of Zanjan University. After 2 weeks of familiarization with exercise protocol, the rats were randomly divided into 5 groups according to the weight as follows: control $(n=8)$, sham $(n=8)$, ET $(n=8)$, ginger $(n=8)$ and ET + ginger $(n=8)$. However, during the study, due to the loss of some rats, the final analysis was performed on the remaining ones: control $(n=8)$, sham $(n=7)$, ET $(n=7)$, ginger $(n=8)$ and ET + ginger $(n=8)$. The rats were kept in polycarbonate cages at $22 \pm 2^{\circ} \mathrm{C}$ with 12 hours of light and 12 hours of darkness and uniform humidity (45-55\%). Water and food were available ad libitum. In addition, all procedures (familiarization, exercise, anesthesia and animal euthanization) were done according to the American Association for Accreditation of Laboratory Animal Care (AAALAC) and confirmed by the Department of Sports Sciences at the Faculty of Humanities of Zanjan University. ET protocol included running on a rodent treadmill with a frequency of 5 days per week which lasted for 8 weeks (Saturday, Sunday, Monday, Wednesday, and Thursday) at certain times (15 to $18 \mathrm{PM}$ ). The sham group, with the exception of running on animals' treadmill and supplements, experienced the same conditions as experimental groups (injections, exercise voices, etc).

\section{Supplying the supplement}

Firstly, the ginger was extracted. To do so, fresh ginger rhizomes were purchased from the store, and after drying the rhizomes in the scientific way, the dried rhizomes were powdered. One gram of the powder was mixed with $1 \mathrm{~L}$ of pure alcohol and then mixed with ethyl acetate solution to reach $100 \mathrm{~mL}(18)$. Then, the solution was injected peritoneally $(100 \mathrm{mg} / \mathrm{kg}$ body weight) three days a week (Saturday, Monday, and Wednesday) in the ginger and ET + ginger groups.

\section{Performing ET protocol}

After familiarization, ET protocol was performed, which included eight weeks of running on the treadmill. The training program was performed at a speed of $10 \mathrm{~m} / \mathrm{min}$ for 30 minutes in the first week with a gradual increase (weekly) until $35 \mathrm{~m} / \mathrm{min}$ for 70 minutes (equal to $80 \%$ $85 \%$ of maximum oxygen consumption) in the last week. In order to avoid overtraining in the fifth week, a reduction was considered (Table 1) (19).

\section{Blood sampling}

Blood samples were obtained 48 hours after the last training session and after 8 hours of fasting. Immediately, the blood samples were transferred to special containers (Falcon) and centrifuged for 10 minutes at a speed of $3000 \mathrm{rpm}$. The serum was stored at a temperature of $-80^{\circ} \mathrm{C}$ until the measurement of the factors.

\section{Determination of liver enzymes}

The measurement of the levels of alanine transferase and AST was done based a method recommended by International Federation of Clinical Chemistry and

Table 1. Endurance training protocol
\begin{tabular}{lcccccccc}
\hline Week & $\mathbf{1}$ & $\mathbf{2}$ & $\mathbf{3}$ & $\mathbf{4}$ & $\mathbf{5}$ & $\mathbf{6}$ & $\mathbf{7}$ & $\mathbf{8}$ \\
\hline Speed $(\mathrm{m} / \mathrm{min})$ & 10 & 20 & 20 & 25 & 15 & 30 & 30 & 35 \\
Time (min/session) & 30 & 40 & 45 & 50 & 35 & 60 & 70 & 70 \\
\hline
\end{tabular}


Laboratory Medicine (IFCC) using enzymatic kits of Pars Azmoon (1-400-019 and 1-400-018). This method has the capability to measure up to 0.16 photon absorption changes at $340 \mathrm{~nm}$.

Determination of MDA and enzymatic activity of hepatic superoxide dismutase

Forty-eight hours after the last training session and after 8 hours of fasting, the animals were euthanized and tissue samples were taken. Immediately, liver tissue was taken and placed in micro-tubes and kept in a freezer at $-80^{\circ} \mathrm{C}$ for the next measurement. Afterwards, $50 \mathrm{mg}$ of liver tissue was placed in $2 \mathrm{~mL}$ homogenous phosphate buffer solution and homogenized in a homogenizer for a minimum of 4 minutes. Then, the tube containing the suspension was centrifuged for 10 minutes at a speed of $3000 \mathrm{rpm}$. In the next stage, the supernatant was removed and $1 \mathrm{~mL}$ of thiobarbituric acid solution was added at a concentration of $6.7 \mathrm{~g} / \mathrm{L}$. Then, the tube was placed in boiling water for 15 minutes, and after cooling, the resulting solution was used to determine the amount of peroxidation of the lipid by measuring the amount of MDA and to measure the activity of SOD. MDA level was evaluated as a measure of lipid peroxidation in the form of thiobarbituric acid reactive substances (TBARS) using the Esterbauer $\mathrm{H}$, Cheeseman $\mathrm{KH}$ method, and the TBARS values were expressed as millimoles per $\mathrm{mg}$ of protein (20). The activity of the enzyme SOD was measured using rendezvous technique based on its manufacturer's instructions (RANDOX Laboratories Ltd, UK). One unit of SOD is a value of the enzyme inhibiting 50\% of 4-2 iodophenyl, 3-4 nitrofenol, 5-phenyltetrazalium (I.N.T) regeneration reaction under test conditions. We measured the activity using a spectrophotometer at $420 \mathrm{~nm}$ wavelength and expressed as $\mathrm{U} / \mathrm{mg}$ protein (21).

\section{Data analysis}

All the statistical procedures were performed using SPSS version 23.0. Descriptive statistics were used to establish the mean and standard deviation values. First, ShapiroWilk test was used for checking the normality of the data distribution. A one-way analysis of variance (ANOVA) and Tukey post hoc tests were used to determine the significant $(P<0.05)$ differences among the groups in terms of ALT, AST, SOD, and MDA.

\section{Results}

At first, normal distribution of data was examined using Shapiro-Wilk test. The results showed that data in all groups had a normal distribution. Moreover, Levene test showed that variances were homogenous. The results of one-way ANOVA and mean values of ALT, AST, SOD, and MDA in all groups were shown in Table 2. Table 3 shows the results of the Tukey post hoc test.
Table 2. Results of one-way analysis of variance for variables in research groups

\begin{tabular}{|c|c|c|c|c|}
\hline Variables & Groups & Mean $\pm S D$ & $F_{4,32}$ & $P$ value \\
\hline \multirow{5}{*}{ ALT (U/L) } & Control & $53.7 \pm 3.6$ & \multirow{5}{*}{1.74} & \multirow{5}{*}{0.16} \\
\hline & Sham & $50.8 \pm 5.5$ & & \\
\hline & Ginger & $49.3 \pm 7.8$ & & \\
\hline & ET & $58.4 \pm 6.4$ & & \\
\hline & ET + Ginger & $55.4 \pm 11.4$ & & \\
\hline \multirow{5}{*}{ AST (U/L) } & Control & $179.5 \pm 35.05$ & \multirow{5}{*}{0.85} & \multirow{5}{*}{0.50} \\
\hline & Sham & $157.1 \pm 23.4$ & & \\
\hline & Ginger & $167.1 \pm 31.2$ & & \\
\hline & ET & $173.0 \pm 20.3$ & & \\
\hline & ET + Ginger & $161.8 \pm 10.2$ & & \\
\hline \multirow{5}{*}{$\begin{array}{l}\text { SOD (U/mg } \\
\text { protein) }\end{array}$} & Control & $83.8 \pm 14.9$ & \multirow{5}{*}{8.24} & \multirow{5}{*}{0.001} \\
\hline & Sham & $119.5 \pm 20.09$ & & \\
\hline & Ginger & $97.0 \pm 12.9$ & & \\
\hline & ET & $131.7 \pm 18.6$ & & \\
\hline & $\mathrm{ET}+$ Ginger & $130.2 \pm 31.3$ & & \\
\hline \multirow{5}{*}{$\begin{array}{l}\text { MDA }(\mathrm{mm} / \\
\mathrm{mg})\end{array}$} & Control & $0.25 \pm 0.03$ & \multirow{5}{*}{5.76} & \multirow{5}{*}{0.001} \\
\hline & Sham & $0.2 \pm 0.02$ & & \\
\hline & Ginger & $0.28 \pm 0.05$ & & \\
\hline & ET & $0.38 \pm 0.08$ & & \\
\hline & ET + Ginger & $0.37 \pm 0.09$ & & \\
\hline
\end{tabular}

ALT: alanine aminotransferase, AST: aspartate aminotransferase, SOD: superoxide dismutase activity, MDA: Malondialdehyde, control: control group, Sham: Sham, ET: endurance training, ginger: ginger, ET + Ginger: endurance training + ginger. Values are means \pm SD. ${ }^{*}$ Statistically significant $(P<0.05)$

Table 3. The results of Tukey post hoc test for comparison between the groups in terms of ALT, AST, SOD, and MDA

\begin{tabular}{|c|c|c|c|c|c|}
\hline $\begin{array}{l}\text { Dependent } \\
\text { variable }\end{array}$ & $\begin{array}{l}\text { Group } \\
\text { (I) }\end{array}$ & Group (J) & $\begin{array}{c}\text { Mean } \\
\text { Difference } \\
(1-J)\end{array}$ & Std. Error & $P$ value \\
\hline \multirow{10}{*}{$\begin{array}{l}\mathrm{SOD}(\mathrm{U} / \mathrm{mg} \\
\text { protein) }\end{array}$} & \multirow{4}{*}{ Control } & Sham & $-35.6^{*}$ & 10.5 & 0.03 \\
\hline & & Ginger & -13.1 & 10.1 & 0.69 \\
\hline & & ET & $-47.8^{*}$ & 10.5 & 0.001 \\
\hline & & $\mathrm{ET}+$ Ginger & $-46.4^{*}$ & 10.5 & 0.001 \\
\hline & \multirow{3}{*}{ Sham } & Ginger & 22.5 & 10.5 & 0.22 \\
\hline & & ET & -12.1 & 10.8 & 0.79 \\
\hline & & $\mathrm{ET}+$ Ginger & -10.7 & 10.8 & 0.85 \\
\hline & \multirow{2}{*}{ Ginger } & ET & $-34.7^{*}$ & 10.5 & 0.01 \\
\hline & & $\mathrm{ET}+$ Ginger & $-33.3^{*}$ & 10.5 & 0.02 \\
\hline & ET & ET + Ginger & 1.4 & 10.8 & 1.00 \\
\hline \multirow{10}{*}{$\begin{array}{l}\mathrm{MDA}(\mathrm{Mm} / \\
\mathrm{mg})\end{array}$} & \multirow{4}{*}{ Control } & ET & -0.01 & 0.03 & 0.98 \\
\hline & & Ginger & -0.02 & 0.03 & 0.90 \\
\hline & & ET & $-0.1^{*}$ & 0.03 & 0.008 \\
\hline & & $\mathrm{ET}+$ Ginger & $-0.1^{*}$ & 0.03 & 0.01 \\
\hline & \multirow{3}{*}{ Sham } & Ginger & -0.01 & 0.03 & 0.90 \\
\hline & & ET & $-0.1^{*}$ & 0.03 & 0.03 \\
\hline & & ET+ Ginger & -0.09 & 0.03 & 0.06 \\
\hline & \multirow{2}{*}{ Ginger } & ET & -0.09 & 0.03 & 0.06 \\
\hline & & $\mathrm{ET}+$ Ginger & -0.08 & 0.03 & 0.09 \\
\hline & ET & $\mathrm{ET}+$ Ginger & -0.007 & 0.03 & 1.00 \\
\hline
\end{tabular}

ALT: alanine aminotransferase, AST: aspartate aminotransferase, SOD: superoxide dismutase activity, MDA: Malondialdehyde, control: control group, Sham: Sham, ET: endurance training, ginger: ginger, ET + Ginger: endurance training + ginger. ${ }^{*}$ The mean difference is significant at the 0.05 level. 


\section{Serum ALT}

The results of ANOVA showed no significant differences in serum ALT between groups $\left(\mathrm{F}_{4.32}=1.7, P=0.16\right)$ (Table 2). In other words, training along with ginger consumption did not affect the serum ALT levels in the studied groups.

\section{Serum AST}

The results of ANOVA showed no significant difference among the groups in serum AST $\left(\mathrm{F}_{4.32}=0.85, P=0.50\right)$ (Table 2). In other words, training coupled with ginger consumption did not affect the serum AST levels in the studied groups.

\section{Liver Tissue SOD Activity}

The results of the one-way analysis of variance showed that there was a significant difference among the studied groups in liver SOD activity $\left(\mathrm{F}_{4.32}=8.24, P=0.001\right)$ (Table 2$)$. Tukey post hoc test also showed that the SOD activity of the liver in ET group $(131.7 \pm 18.6, P=0.001)$, ET + ginger group $(130.2 \pm 31.3, P=0.001)$, and sham group $(119.5 \pm 20.09$, $P=0.015)$ significantly increased in comparison with the control group (83.8 \pm 14.9$)$. Moreover, the activity of liver SOD in ET group $(131.7 \pm 18.6, P=0.018)$ and $\mathrm{ET}+$ ginger group $(130.2 \pm 31.3, P=0.026)$ significantly increased in comparison with the ginger group $(97.00 \pm 12.96)$ (Table 2 and Figure 1).

\section{Liver tissue MDA}

The results of the one-way analysis of variance showed that there was a significant difference in liver MDA levels among the studied groups $\left(\mathrm{F}_{4.32}=5.76, P=0.001\right)$ (Table 2 and Figure 2). The results of Tukey's post hoc test showed that the liver MDA levels in the ET group $(0.38 \pm 0.08$, $P=0.008)$ and ET + Ginger group $(0.37 \pm 0.09, P=0.013)$ significantly increased in comparison with the control group $(0.25 \pm 0.03)$. Moreover, liver MDA levels in the ET group $(0.38 \pm 0.08)$ significantly increased in comparison with the sham group $(0.27 \pm 0.02, P=0.037)$ (Table 3 and Figure 2).

\section{Discussion}

Overall, the results of this study showed that 8 weeks of ET with ginger consumption did not affect the serum levels of AST and ALT liver enzymes but significantly affected liver tissue MDA levels and SOD activity of liver tissue in Wistar rats.

Aspartate Aminotransferase and Alanine Aminotransferase

The results showed that 8 weeks of ET with ginger consumption had no significant effect on serum levels of liver enzymes (ALT and AST). Nonetheless, serum AST and ALT levels in training groups using ginger with ET compared to ET group had a non-significant decrease. The lack of alteration of serum ALT level in the training group was similar to the study of Barzegarzadeh-Zarandi and Dabidy-Roshan who witnessed a significant increase in the level of ALT after 6 and 12 weeks of continuous and periodic exercises (22). In addition, this lack of change is inconsistent with the findings of Kim et al (23) and Kratz et al (24), who reported an increase in ALT after about 200 $\mathrm{km}$ and marathon running. It has been stated that intensive sports activities cause damage to liver cells and increase the release of liver enzymes in the blood (25) by increasing free radical production (26). Therefore, it seems that either the production of free radicals was not sufficient to increase the release of enzymes, or that the time of the measurement of the factors was different from that of other studies.

However, the insignificant decrease in serum AST and ALT in the ET + ginger group compared to the ET group was somehow consistent with the findings of Beydilli et al (26), who observed that the use of silibinin reduced the level of AST and ALT enzymes. The production of free radicals in the body impairs liver function and by

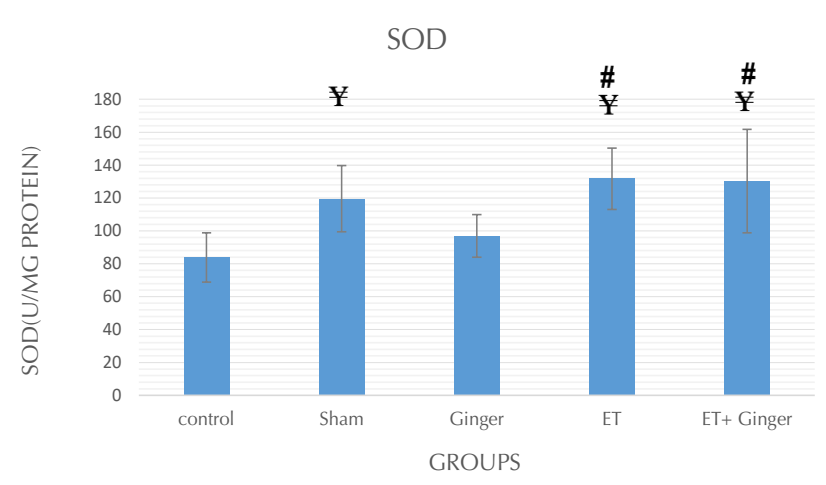

Figure 1. Changes in the activity of liver SOD in the studied groups after 8 weeks.

SOD: superoxide dismutase activity, control: control group, Sham: Sham, ET: endurance training, ginger: ginger, ET + ginger: endurance training + ginger. Values are means \pm SD. ${ }^{*}$ Statistically significant $(P<0.05) ; ¥ \mathrm{~A}$ significant difference compared to the control group $(P<0.05)$; \# A significant difference compared to the ginger group $(P<0.05)$.

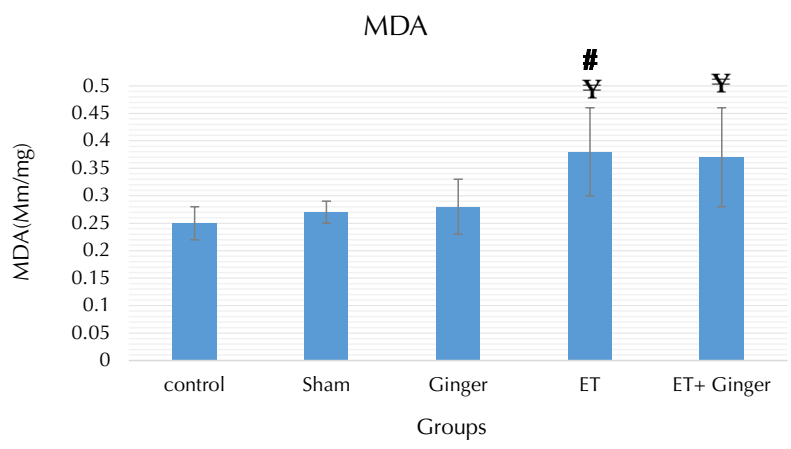

Figure 2. Changes in the liver tissue malondialdehyde in the studied groups after 8 weeks

MDA: Malondialdehyde, control: control group, Sham: Sham, ET: endurance training, ginger: ginger, ET + Ginger: endurance training + ginger. Values are means \pm SD. * Statistically significant $(P<0.05)$. $¥$ A significant difference compared to the control group $(P<0.05)$; \# A significant difference compared to the sham group $(P<0.05)$. 
damaging liver cells increases the liver enzymes of AST and ALT. It seems that ginger, due to its antioxidant property (27), prevents further damage to the liver cells thus leading to an unnecessary reduction in the presence of AST and serum ALT in the training group using ginger compared to ET group. Nevertheless, one of the limitations of this study was the lack of measurement of alkaline phosphatase enzyme and some factors indicating the presence of free radicals. Therefore, we recommend that these findings be considered for better conclusions in future studies.

\section{Liver MDA and SOD}

Considering the enzymatic activity of liver SOD, the results showed that liver enzyme activity in the EE group as well as $\mathrm{EE}+$ ginger significantly increased compared to the control group and ginger group. Furthermore, the activity of liver SOD in the sham group significantly increased compared to the control group. Regarding the level of liver MDA, the results revealed that MDA level in ET group as well as ET + ginger increased significantly compared to the control group. Even MDA levels in the ET group significantly increased compared to the sham group (showing a direct effect of the exercise on hepatic MDA elevation). In other words, ginger has no effect on the level of liver enzyme activity and liver MDA. The results of previous studies concerning the effect of regular training on the level of oxidative stress indices are highly controversial. The reasons for these contradictory results are probably the type of subject, experience of the subject, the studied tissue, training type, and the duration and intensity of the workout. For instance, Esterbauer et al concluded that the longer the swimming time of the rats, the more peroxidation (20).

In the present study, the time and speed of the training group reached the highest in the final weeks, and with increasing activity time, the incidence of lipid peroxidation (probably because of increased superoxide leakage from the mitochondrial electron transfer chain) in ET group as well ET + Ginger significantly increased compared to the control group. Therefore, given the differences in the nature of the types of sports activities, the level of readiness of the subjects, the type of tissue examined, the duration and intensity of the activity, and so on, there can be no definite conclusion regarding lipid peroxidation being affected by regular exercise. In conclusion, one can state that as the duration of training and intensity increases, an increase in lipid peroxidation occurs; however, by regular training and due to adaptations that are likely to occur in the antioxidant system of the body, lipid peroxidation may reduce or even stop (28). While training, several factors are involved in damage to the liver, including hypoxia, xanthine oxidase activity, and increased body temperature (29). During training, due to increased exercise intensity, liver blood flow decreases. In other words, during the intensive exercises in comparison with resting conditions, the liver blood flow decreases to $18 \%$, leading to hypoxia in the liver. Hypoxia causes depletion of adenine nuclei in the cell, including ATP, disturbed sodium mitochondria, mitochondria membrane cell, accumulation of toxin metabolites in the liver cells, malabsorption of the materials necessary for energy production, disorders of calcium homeostasis, and activation of phospholipase enzyme. Finally, the membrane decomposes into two layers of the liver (29). Under acute or chronic hypoxia conditions, there is a balance between oxidative stress and antioxidant systems ultimately leading to cell death.

Another hypothesis is related to the activity of xanthine oxidase. During training, the conversion of xanthine dehydrogenase, with a high concentration in the liver tissue, to xanthine oxidase, and then the synthesis of superoxide anions and other active oxygen species such as $\mathrm{H}_{2} \mathrm{O}_{2}$ cause oxidative stress and ultimately, the increased levels of oxidative stress, including MDA, are found in the liver tissue (29). Among other factors, damaging the liver cells can cause an increase in body temperature during training. Given the increase in body metabolism during training, body temperature can reach even more than $40^{\circ} \mathrm{C}$ (29). Under these conditions, the formation of superoxide is accelerated by xanthine oxidase and liver glutathione depletion, oxidative stress occurs in the liver, and MDA level of the liver tissue increases (30). Among other factors that might end in oxidative stress, as well as lipid peroxidation and liver damage are the activity of catecholamines and self-oxidation, prostatic metabolism, NADPH oxidase, and macrophage activity (31). In conclusion, one can claim that at least in high-intensity exercises, the liver tissue faces some degree of damages. Nonetheless, limited information is available on its extent, the duration and severity of acute training and the extent of these liver damages (32).

On the other hand, the expectation exists; that is, by increasing SOD, MDA level decreases in the liver tissue. However, a significant increase in lipid peroxidation in the training groups would challenge the results (i.e., the antioxidant system is not fully able to stop the lipid peroxidation process). Studies show that the intensity and duration of physical activity and the type of subject are important variables that can change the level of physical activity effects on the oxidative stress indices of the body. Indeed, the less the intensity of activity and the shorter the duration are, the lower the incidence of lipid peroxidation would be, not facing a serious challenge in triggering specific antioxidant responses (28). However, seemingly, in the recent study, the duration and severity of the activity were in a way that increased the incidence of lipid peroxidation.

The most important finding of the study was that MDA and SOD levels of liver tissue in the ginger extract group were not significantly different from those of the training group. The results also showed that liver enzyme activity in the training group, as well as the ginger + training group, significantly increased compared to the control group. 
This was not consistent with the results of Taghizadeh Afshari et al reporting peroxidation of fat and increase of the antioxidant capacity of rats treated with ginger (33). Inconsistent with the present study, Heeba and AbdElghany showed that after 4 weeks of using ginger, MDA and antioxidant enzymes activities decreased in Wistar rats (34). Furthermore, Manju and Nalini examined the effect of 15 weeks of ginger consumption on the activity of antioxidant enzymes and lipid peroxidation index in mice with colon cancer, reporting that lipid peroxidation index in ginger-treated rats significantly decreased (16). In another study, Mallikarjuna et al also stated that 4 weeks of ginger consumption had anxiolytic effects and reduced MDA in the liver tissues of rats (35). Other studies have considered one of the effective mechanisms of ginger in reducing levels of MDA by reducing liver and lipid peroxidation (36), which was not attained in the present study. Hence, it seems that more studies are needed to obtain more accurate results.

\section{Conclusion}

Overall, it seems that strenuous ET stimulates and increases the activity of liver SOD and increases liver MDA, and ginger consumption does not change this process. In other words, ginger had neither increasing nor decreasing effect. Therefore, this study does not support protective effects of ginger in reducing liver enzymes and improving the antioxidant status. It is also likely that high-intensity training does not provide the opportunity to improve the antioxidant system of the body. Therefore, a more accurate conclusion requires further study.

Conflicts of Interests

The authors declare no competing interests.

\section{Ethical Approval}

The study protocol was approved by the Ethics Committee of Sports Sciences Research Institute of Iran (IR.SSRC.REC.1397.018) on January 23, 2019.

\section{Authors' Contributions}

$\mathrm{ZI}, \mathrm{A} G \mathrm{H}$ : designed the study, carried out data collection.

$\mathrm{ZI}, \mathrm{MU}, \mathrm{A} \mathrm{GH}, \mathrm{A}$ R: participation in analysis and carried out data collection. $\mathrm{ZI}, \mathrm{M} \mathrm{U}, \mathrm{A} \mathrm{R}, \mathrm{A} \mathrm{GH}$ : contributed to collected all of samples. Z I, A GH, A R:contributed to study design and manuscript drafting. all authors approved the final version manuscript.

\section{Funding/Support}

The budget for this research has been provided by the members of the research team and also was supported by the Research Deputy of ZAnjan University.

\section{Acknowledgements}

This article was derived from a master's degree thesis in Applied Exercise Physiology (2572100) which was registered at the Iranian Research Institute for Information Science and Technology database (IranDoc) in collaboration with Zanjan University. We appreciate Zanjan University for the contribution to and financial support for conducting this research.
References

1. Cooper CE, Vollaard NB, Choueiri T, Wilson MT. Exercise, free radicals and oxidative stress. Biochem Soc Trans. 2002;30(2):280-5.

2. Gharakhanlou R, Afzalpour ME, Gaeini AA, Rahnama N. Effects of aerobic exercises on the serum paraoxonase 1/arylesterase activity and lipid profile in non-active healthy men. Int J Sports Sci Eng. 2007;1(2):105-12.

3. Amirabadi F, Asadi MR, Tabrizi A. The effect of endurance training and use of cinnamon supplement on antioxidant index and lipid peroxidation as additional care in middle-aged female diabetic type II patients. Journal of Diabetes Nursing. 2016;4(3):48-59.

4. Fridovich I. Superoxide dismutases. Adv Enzymol Relat Areas Mol Biol. 1986;58:61-97. doi: 10.1002/9780470123041.ch2.

5. Adams AK, Best TM. The role of antioxidants in exercise and disease prevention. Phys Sportsmed. 2002;30(5):37-44. doi: 10.3810/psm.2002.05.281.

6. Powers SK, Jackson MJ. Exercise-induced oxidative stress: cellular mechanisms and impact on muscle force production. Physiol Rev. 2008;88(4):1243-76. doi: 10.1152/ physrev.00031.2007.

7. Liu J, Yeo HC, Overvik-Douki E, Hagen T, Doniger SJ, Chyu DW, et al. Chronically and acutely exercised rats: biomarkers of oxidative stress and endogenous antioxidants. J Appl Physiol (1985). 2000;89(1):21-8. doi: 10.1152/jappl.2000.89.1.21.

8. Terohid S, Mirazi M, Sarihi A. Study of hepatoprotective effect of Malva neglecta L. hydroethanolic leaf extract in male rat Induced with carbon tetrachloride. Journal of Cell \& Tissue. 2015;6(1):31-42.

9. Bloomer RJ, Goldfarb AH. Anaerobic exercise and oxidative stress: a review. Can J Appl Physiol. 2004;29(3):245-63. doi: 10.1139/h04-017.

10. Urso ML, Clarkson PM. Oxidative stress, exercise, and antioxidant supplementation. Toxicology. 2003;189(1-2):4154. doi: 10.1016/s0300-483x(03)00151-3.

11. Walsh PC. Effects of long-term vitamin E supplementation on cardiovascular events and cancer: a randomized controlled trial. J Urol. 2005;174(5):1823-4. doi: 10.1097/01. ju.0000183077.52404.ec.

12. Hosseinzadeh H, Sadeghnia HR. Effect of safranal, a constituent of Crocus sativus (saffron), on methyl methanesulfonate (MMS)-induced DNA damage in mouse organs: an alkaline single-cell gel electrophoresis (comet) assay. DNA Cell Biol. 2007;26(12):841-6. doi: 10.1089/dna.2007.0631.

13. Atashak S, Piri M, Jafari A, Azarbayjani MA. Effects of 10 week resistance training and ginger consumption on C-reactive protein and some cardiovascular risk factors in obese men. Physiology and Pharmacology. 2010;14(3):318-28.

14. Mashhadi NS, Ghiasvand R, Askari G, Hariri M, Darvishi L, Mofid MR. Anti-oxidative and anti-inflammatory effects of ginger in health and physical activity: review of current evidence. Int J Prev Med. 2013;4(Suppl 1):S36-42.

15. Ali BH, Blunden G, Tanira MO, Nemmar A. Some phytochemical, pharmacological and toxicological properties of ginger (Zingiber officinale Roscoe): a review of recent research. Food Chem Toxicol. 2008;46(2):409-20. doi: 10.1016/j.fct.2007.09.085.

16. Manju V, Nalini N. Effect of ginger on lipid peroxidation and antioxidant status in 1, 2-dimethyl hydrazine induced experimental colon carcinogenesis. J Biochem Technol. 2010;2(2):161-7.

17. Mokhtari M, Shariati M, Khodaparast L. Assessment of the effects of the hydro-alcoholic extract of Mentha pulegium leaves on liver function test in male rat. Journal of Sabzevar 
University of Medical Sciences. 2008;15(48):73-81.

18. Rahmanian F, Hemayatkhah Jahromi V, Kargar H. Effects of Zingiber officinale Roscoe extract on spermatogenesis and hormonal axis of pituitary Gonad in Immature Balb/C mice. Journal of Science (Kharazmi University). 2010;10(3):915-22.

19. Gorzi A, Ekradi S, Rahmani A. The effect of high intensity endurance training on antioxidant defense and lipid peroxidation of male Wistar rats. J Sports Sci. 2018;10(3):33345. doi: 10.22059/jsb.2018.235524.1180.

20. Esterbauer H, Schaur RJ, Zollner H. Chemistry and biochemistry of 4-hydroxynonenal, malonaldehyde and related aldehydes. Free Radic Biol Med. 1991;11(1):81-128. doi: 10.1016/08915849(91)90192-6.

21. Kheradmand A, Alirezaei M, Asadian P, Rafiei Alavi E, Joorabi S. Antioxidant enzyme activity and MDA level in the rat testis following chronic administration of ghrelin. Andrologia. 2009;41(6):335-40. doi: 10.1111/j.1439-0272.2009.00932.x.

22. Barzegarzadeh-Zarandi $H$, Dabidy-Roshan V. Changes in some liver enzymes and blood lipid level following interval and continuous regular aerobic training in old rats. Journal of Shahrekord University of Medical Sciences. 2012;14(5):13-23.

23. Kim HJ, Lee YH, Kim CK. Biomarkers of muscle and cartilage damage and inflammation during a $200 \mathrm{~km}$ run. Eur J Appl Physiol. 2007;99(4):443-7. doi: 10.1007/s00421-006-0362-y.

24. Kratz A, Lewandrowski KB, Siegel AJ, Chun KY, Flood JG, Van Cott EM, et al. Effect of marathon running on hematologic and biochemical laboratory parameters, including cardiac markers. Am J Clin Pathol. 2002;118(6):856-63. doi: 10.1309/14ty-2tdj$1 \mathrm{x} 0 \mathrm{y}-1 \mathrm{v} 6 \mathrm{v}$.

25. Nikolaidis MG, Kyparos A, Hadziioannou M, Panou N, Samaras $\mathrm{L}$, Jamurtas AZ, et al. Acute exercise markedly increases blood oxidative stress in boys and girls. Appl Physiol Nutr Metab. 2007;32(2):197-205. doi: 10.1139/h06-097.

26. Beydilli H, Yilmaz N, Cetin ES, Topal Y, Celik OI, Sahin C, et al. Evaluation of the protective effect of silibinin against diazinon induced hepatotoxicity and free-radical damage in rat liver. Iran Red Crescent Med J. 2015;17(4):e25310. doi: 10.5812/ ircmj.17(4)2015.25310.

27. Shirdel Z, Mirbadalzadeh R, Madani H. Antidiabetic and antilipidemic effect of ginger in alloxan monohydrate diabetic rats in comparison with glibenclamide. Iranian Journal of Diabetes and Lipid Disorders. 2009;9(1):7-15.

28. Gaeini AA, Sheykh Aleslami Vatani, Alameh AA, Ravasi AA, Kordi MR, Mogharnasi $M$, et al. Effect of endurance training and a detraining period on lipid peroxidation and antioxidant system in Wistar rats. Journal of Movement Science \& Sports. 2008;6(11):51-63. [Persian].

29. Skibba JL, Gwartney EA. Liver hyperthermia and oxidative stress: role of iron and aldehyde production. Int J Hyperthermia. 1997;13(2):215-26. doi: 10.3109/02656739709012384.

30. Wynne JM, Mack S, McRae D, Pillay SP, Potts J, Boffinger $C$, et al. Portal vein perfusion of the isolated rat liver: some markers of hyperthermic liver damage. Aust J Exp Biol Med Sci. 1984;62(Pt 1):73-80. doi: 10.1038/icb.1984.7.

31. Bakonyi T, Radak Z. High altitude and free radicals. J Sports Sci Med. 2004;3(2):64-9.

32. Flamm SD, Taki J, Moore R, Lewis SF, Keech F, Maltais F, et al. Redistribution of regional and organ blood volume and effect on cardiac function in relation to upright exercise intensity in healthy human subjects. Circulation. 1990;81(5):1550-9. doi: 10.1161/01.cir.81.5.1550.

33. Afshari AT, Shirpoor A, Farshid A, Saadatian R, Rasmi $Y$, Saboory E, Ilkhanizadeh B, Allameh A. The effect of ginger on diabetic nephropathy, plasma antioxidant capacity and lipid peroxidation in rats. Food chemistry. 2007 Jan 1;101(1):14853.

34. Heeba GH, Abd-Elghany Ml. Effect of combined administration of ginger (Zingiber officinale Roscoe) and atorvastatin on the liver of rats. Phytomedicine. 2010;17(14):1076-81. doi: 10.1016/j.phymed.2010.04.007.

35. Mallikarjuna K, Sahitya Chetan P, Sathyavelu Reddy K, Rajendra W. Ethanol toxicity: rehabilitation of hepatic antioxidant defense system with dietary ginger. Fitoterapia. 2008;79(3):174-8. doi: 10.1016/j.fitote.2007.11.007.

36. Taghizadeh Afshari A, Shirpoor A, Farshid A, Saadatian R, Rasmi Y, Saboory E, et al. The effect of ginger on diabetic nephropathy, plasma antioxidant capacity and lipid peroxidation in rats. Food Chem. 2007;101(1):148-53. doi: 10.1016/j.foodchem.2006.01.013 